\title{
Study on the Plate Correlation of Financial Distress Prediction of Chinese Listed Companies
}

\author{
Jiayi Hu \\ School of Economics, Shanghai University, Shanghai 200444, China \\ winjiayi@163.com
}

Keywords: Financial Distress Prediction, Listed companies on different plates, Probit model, Logit model.

\begin{abstract}
With the rapid development of China's capital market, listed companies have become an important factor in promoting economic growth, its healthy development is directly related to the healthy and sustainable development of China's national economy. Therefore, the prediction of the financial risk of listed companies is of great practical significance for managers, investors and government regulators.This paper first from the definition of financial distress, selecting the relevant financial indicators from six aspects, to construct the Probit model and Logit model, two models are constructed to study the influence factors of financial distress of listed companies of different plates in China. Finally, the prediction accuracy of Probit model and Logit model are compared.
\end{abstract}

\section{Introduction}

With the rapid development of China's capital market, the securities market has become increasingly active, and the number of listed companies has increased year by year. It can be said that the healthy development of listed companies is directly related to the healthy and sustainable development of China's national economy.

But in recent years, in view of China's macroeconomic environment, since the beginning of the two quarter of 2012, Chinese GDP growth rate began to fall, the stage of economic growth has undergone fundamental changes, showing the overall development of the economy has changed from high speed growth to middle and high speed growth, the continuous optimization and upgrading of the economic structure, from factor driven, investment driven to innovation driven, China's economic development has entered a new normal state. In 2015, China's GDP grew by $6.9 \%$, and its growth rate decreased by 0.4 percentage points in 2014, the lowest annual increase since 1990. In 2016, China's macro economy continued to slow down, and the downward pressure on the economy continued to increase. Under the severe macroeconomic situation, the risk of enterprise capital chain breaking will be greatly increased, so the listed companies in financial distress prediction has very important practical significance for the company managers, investors and government regulators.

In all listed companies, the financial status of listed companies with different plates is different, if we can study separately, we can find that the factors that affect the financial difficulties of different plate enterprises are different.

\section{Review of research methods of financial distress}

The research of enterprise financial distress prediction began in 1960s. The prediction methods of financial distress are divided into two categories: traditional statistical methods and artificial intelligence methods.

The traditional statistical method was first started in 1932, Fitzpatrick used single variable analysis to do financial early warning analysis. In 1968, Altman applied multivariate discriminant 
analysis to the prediction of financial distress for the first time. The multiple discriminant method made up for the deficiency of single variable analysis and could measure the overall performance quantitatively. In addition, the commonly used statistical methods include the Logit model and the Probit model. The advantage of the two methods lies in solving the problem of non normal data of independent variables in discriminant analysis and being applicable to nonlinear situations.

In 1990s, artificial intelligence methods began to be applied to the prediction of financial distress in enterprises. In 1990, Odom and Sharda used neural network theory to analyze the financial distress of listed companies for the first time. Other commonly used methods are support vector machines, genetic algorithms and so on.

\section{Research design}

\subsection{Definition of financial distress}

In this paper, the definition of financial distress is adopted by Lv Changjiang, $\mathrm{Xu} \mathrm{Li}$ and Zhou Lin (2004), that is, current assets are less than current liabilities. In previous studies, ST companies were often regarded as financial distress companies, but Lv Changjiang, $\mathrm{Xu} \mathrm{Li} \mathrm{and} \mathrm{Zhou} \mathrm{Lin} \mathrm{argued}$ that such a definition was not appropriate. At present, the development of securities market in our country is not perfect. Because the listing qualification has been strictly controlled by the China Securities Regulatory Commission, therefore, the huge demand has made the enterprises whose benefits are poor, known as "shell" resources, have become very hot.

Therefore, when choosing a sample of distressed enterprises, this paper requires that the flow ratio is less than 1 , greater than 0.8 and lasts for two years. For the selection of a normal company, the current ratio is required to be greater than 2 for two consecutive years.

\subsection{Sample selection}

This paper selects the financial distress company of Shanghai and Shenzhen stock markets in 2012-2016 years, simultaneously according to the 1:3 proportion, chooses the financial normal company. All companies are divided into three plate. All data comes from WIND.

2012-2014 years of financial distress company and the financial normal company were used as estimation groups for estimating the parameters of the Probit and Logit models; 2014-2016 years of financial distress company and the financial normal company were used as a validation group to test the predictive power of the Probit and Logit models, The specific distribution is shown in Table 1.

Table 1

\begin{tabular}{|c|c|c|c|c|}
\hline YEAR & \multirow{2}{*}{ PLATE } & Financial Distress Company & Financial Normal Company & Group \\
\cline { 1 - 3 } $2012-2014$ & \multirow{2}{*}{ mainboard } & 130 & 390 & estimation \\
\cline { 3 - 5 } & & 92 & 276 & validation \\
\hline $2014-2016$ & \multirow{2}{*}{ sme board } & 41 & 123 & estimation \\
\cline { 1 - 3 } $2012-2014$ & 31 & 93 & validation \\
\hline $2014-2016$ & & 8 & 24 & estimation \\
\hline $2012-2014$ & \multirow{2}{*}{ start up board } & 10 & 30 & validation \\
\cline { 1 - 3 } & & & &
\end{tabular}

\subsection{Variable selection}

On the basis of previous studies, this paper selects 11 representative financial indicators: Earnings per share(X1), Return on assets(X2), Quick ratio(X3), Equity ratio(X4), Working capital/total assets(X5), Inventory turnover(X6), Accounts receivable turnover(X7), Revenue growth rate(X8), Growth rate of net profit(X9), Sales of goods, services, revenues, cash /revenues(X10), Asset liability ratio(X11). 


\subsection{Model setting}

Whether the enterprise is in financial distress, the "yes" and "no" two states, so this is a two yuan discrete explanatory variable. Probit model and Logit model are two meta choice models commonly used. This paper takes the financial distress company as 1 , the normal company value is 0 , constructs the representative enterprise whether to fall into the financial difficulty two yuan, chooses the explanation variable $Y$.

\subsubsection{Probit model formula:}

$$
\mathrm{Y}_{\mathrm{i}}=\mathrm{F}^{-1}\left(\mathrm{P}_{\mathrm{i}}\right)=\beta_{0}+\beta_{1} \mathrm{x}_{1 \mathrm{i}}+\beta_{2} \mathrm{x}_{2 \mathrm{i}}+\ldots+\beta_{\mathrm{k}} \mathrm{x}_{\mathrm{ki}}+\mu_{\mathrm{i}}
$$

\subsubsection{Logit model formula:}

$$
Y_{i}=\ln \frac{P_{i}}{1-P_{i}}=\beta_{0}+\beta_{1} x_{1 i}+\beta_{2} x_{2 i}+\ldots+\beta_{k} x_{k i}+\mu_{i}
$$

In formula, $\beta 0$ is constant, $\beta 1--\beta \mathrm{k}$ are estimation coefficient.

\subsection{Comparison of the effectiveness of the model}

In this paper, the goodness of fit test is used to compare the effectiveness of the Probit model and the Logit model.

\section{Empirical analysis}

The three validation group data are imported into EViews6 software for empirical analysis. Because there are more financial indicators are not significant, so the stepwise Probit regression method and the stepwise Logit regression method are adopted. The significant variables are introduced into the model one by one, and the non-significant variables and the redundant variables are eliminated.

\subsection{Start up board}

Table 2 Probit model's regression results

\begin{tabular}{|c|c|c|c|c|}
\hline Variable & Coefficient & Std. Error & z-Statistic & Prob. \\
\hline C & -8.24364 & 3.943693 & -2.090335 & 0.0366 \\
\hline X8 & 0.036444 & 0.025321 & 1.439258 & 0.1501 \\
\hline X11 & 0.148507 & 0.066089 & 2.247067 & 0.0246 \\
\hline \multicolumn{4}{|c|}{ McFadden R^2=0.814519 LR=29.31411 P=0.0000 } \\
\hline
\end{tabular}

McFadden $\mathrm{R}^{\wedge} 2=0.814519, \mathrm{P}=0$, and the model fit was very good. The 3 coefficients reject the original hypothesis at the $15 \%$ significance level, indicating that the variables are significant.

Table 3 Lrobit model's regression results

\begin{tabular}{|c|c|c|c|c|}
\hline Variable & Coefficient & Std. Error & z-Statistic & Prob. \\
\hline $\mathrm{C}$ & 0 & 6.695263 & -2.10566 & 0.0352 \\
\hline $\mathrm{X} 8$ & 0.061341 & 0.043347 & 1.415118 & 0.157 \\
\hline $\mathrm{X} 11$ & 0.255392 & 0.114878 & 2.223153 & 0.0262 \\
\hline \multicolumn{5}{|c|}{ McFadden $\mathrm{R} \wedge 2=0.80749 \mathrm{LR}=29.06112 \quad \mathrm{P}=0.0000$} \\
\hline
\end{tabular}

McFadden $\mathrm{R}^{\wedge} 2=0.80749, \mathrm{P}=0$, and the model fit was very good. The 3 coefficients reject the original hypothesis at the $15 \%$ significance level, indicating that the variables are significant.

Through the stepwise regression method, the two models retained two financial indicators: Revenue growth rate(X8), Asset liability ratio(X11). And the fitting degree of Probit model is better than that of Logit model. 


\subsection{SME board}

Table 4 Probit model's regression results

\begin{tabular}{|c|c|c|c|c|}
\hline Variable & Coefficient & Std. Error & z-Statistic & Prob. \\
\hline $\mathrm{C}$ & -4.211338 & 0.973852 & -4.324414 & 0 \\
\hline $\mathrm{X} 2$ & -0.094659 & 0.037519 & -2.522927 & 0.0116 \\
\hline $\mathrm{X} 11$ & 0.140359 & 0.029218 & 4.803932 & 0 \\
\hline \multicolumn{5}{|c|}{ McFadden $\mathrm{R}^{\wedge} 2=0.856374 \quad$ LR $=157.9547 \quad \mathrm{P}=0.0000$} \\
\hline
\end{tabular}

McFadden $\mathrm{R}^{\wedge} 2=0.856374, \mathrm{P}=0$, and the model fit was very good. The 3 coefficients reject the original hypothesis at the $5 \%$ significance level, indicating that the variables are significant.

Table 5 Lrobit model's regression results

\begin{tabular}{|c|c|c|c|c|}
\hline Variable & Coefficient & Std. Error & z-Statistic & Prob. \\
\hline $\mathrm{C}$ & -7.57505 & 1.898679 & -3.989643 & 0.0001 \\
\hline $\mathrm{X} 2$ & -0.166371 & 0.075243 & -2.211108 & 0.027 \\
\hline $\mathrm{X} 11$ & 0.250172 & 0.053542 & 4.672432 & 0 \\
\hline \multicolumn{5}{|c|}{ McFadden R^2=0.85012 LR=156.8011 P=0.0000 } \\
\hline
\end{tabular}

McFadden $\mathrm{R}^{\wedge} 2=0.85012, \mathrm{P}=0$, and the model fit was very good. The 3 coefficients reject the original hypothesis at the $5 \%$ significance level, indicating that the variables are significant.

Through the stepwise regression method, the two models retained two financial indicators: Return on assets(X2), Asset liability ratio(X11). And the fitting degree of Probit model is better than that of Logit model.

\subsection{Mainboard}

Table 6 Probit model's regression results

\begin{tabular}{|c|c|c|c|c|}
\hline Variable & Coefficient & Std. Error & z-Statistic & Prob. \\
\hline C & 1.136242 & 0.184709 & 6.15152 & 0 \\
\hline X2 & -0.03836 & 0.011971 & -3.204253 & 0.0014 \\
\hline X3 & -1.015887 & 0.193273 & -5.25624 & 0 \\
\hline X5 & -0.017287 & 0.002914 & -5.932036 & 0 \\
\hline \multicolumn{4}{|c|}{ McFadden $\mathrm{R}^{\wedge} 2=0.481026 \quad$ LR=281.3177 $\quad \mathrm{P}=0.0000$} \\
\hline
\end{tabular}

McFadden $\mathrm{R}^{\wedge} 2=0.481026, \mathrm{P}=0$, and the model fit was very good. The 4 coefficients reject the original hypothesis at the $5 \%$ significance level, indicating that the variables are significant.

Table 7 Lrobit model's regression results

\begin{tabular}{|c|c|c|c|c|}
\hline Variable & Coefficient & Std. Error & z-Statistic & Prob. \\
\hline C & 2.147874 & 0.394863 & 5.439548 & 0 \\
\hline X2 & -0.051112 & 0.024883 & -2.054121 & 0.04 \\
\hline X3 & -1.414596 & 0.42094 & -3.360565 & 0.0008 \\
\hline X5 & -0.071873 & 0.010784 & -6.66506 & 0 \\
\hline \multicolumn{4}{|c|}{ McFadden R^2=0.548568 LR=320.8183 P=0.0000 } \\
\hline
\end{tabular}

McFadden $\mathrm{R}^{\wedge} 2=0.548568, \mathrm{P}=0$, and the model fit was very good. The 4 coefficients reject the original hypothesis at the $5 \%$ significance level, indicating that the variables are significant.

Through the stepwise regression method, the two models retained two financial indicators: Return on assets(X2), Quick ratio(X3), Working capital/total assets(X5). And the fitting degree of Lrobit model is better than that of Probit model. 


\section{Conclusion}

(1) The financial indicators affecting the financial distress of listed companies of the three plates are different:

The financial indicators that affect gem enterprises are Revenue growth rate and Asset liability ratio. The regression results show that the higher the revenue is, the more likely the enterprise is to fall into financial distress,it seems inconsistent with expectations, analysis its causes, enterprises in the short term growth too fast, will bring a variety of problems, such as operating income growth is included in the credit sales, if not receive payment credit sales are likely to fall into financial distress. In addition, the sources of funds in the enterprise, the more funds from the debt, the enterprise into financial difficulties, the risk is greater.

The financial indicators that affect small and medium enterprises are Return on assets and Asset liability ratio. The regression results show that the higher the asset utilization efficiency of small and medium board enterprises, the less likely it is to fall into financial distress; and the more funds from the debt, the more enterprises are in financial distress, the greater the risk.

The financial indicators that affect mainboard enterprises are Return on assets, Quick ratio,Working capital/total assets. The regression results show that the stronger the profitability and solvency of the main board enterprises, the less likely it is to fall into financial distress.

(2) Forecast for gem and sme board, the fitting degree of Probit model is better than that of Logit model. Forecast for motherboards, the fitting degree of Logit model is better than that of Probit model.

\section{References}

[1] Fitzpatrick P J.A comparison of successful industrial enterprises with those of failed firms [J]. Certified Public Accountant, 1932, 2: 589-731.

[2] Martin,D. Early. Warning of banking failure:A logit regression approach [J]. Journal of Banking and Finance, 1977, 1(3): 249-276.

[3] Lu Changjiang, Xu Lili, Zhou Lin. Comparative Analysis of Corporate Financial Distress and Financial Bankruptcy [J]. Economic Research, 2004(8): 64-73. 